\title{
A OLÍMPICA 12 DE PÍNDARO: TRADUÇÃO E COMENTÁRIO
}

\author{
Gustavo Henrique Montes Frade` \\ Universidade Federal de Minas Gerais
}

\begin{abstract}
This study proposes an interpretation of Pindar's Olympian 12 with particular attention to the theme of contingency (according to Aristotle, "that which may be otherwise") in relation to human action. As the course of the athlete's life and of the political history of Himera, the poem and its water images move through uncertainties and reach the accomplishment. Although Pindar recognizes the risks of hope, he shows how the constant variations of human life and the impossibility of knowing the future can result in a positive reversion of conditions in which an adverse situation leads to achievement, even when it is unlikely.

KEYWORDS: Olympian 12; epinikion; Pindar; Greek lyric poetry; contingency.
\end{abstract}

\section{Tradução'}

LYMPIA XII

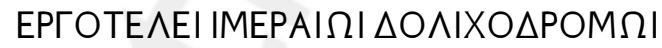

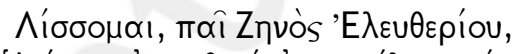
бтр.

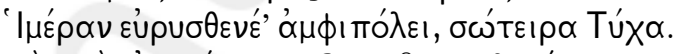

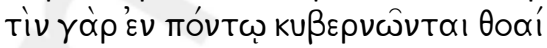

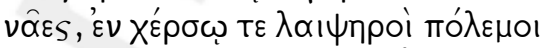

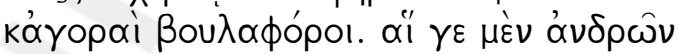

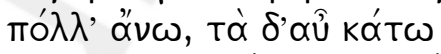

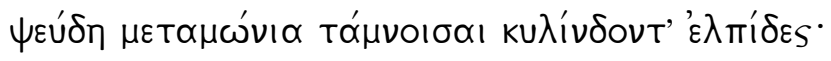

^ghmfrade@gmail.com

${ }^{1} \mathrm{O}$ texto grego utilizado é o de Maehler e Snell. Cf. Píndaro. Pindari carmina cum fragmentis. Editado por H. Maehler (post B. Snell). Leipzig: Teubner, 1971 (todas as traduções de texto grego citadas no artigo são de minha autoria). 


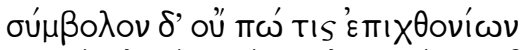
’’ $v T$.

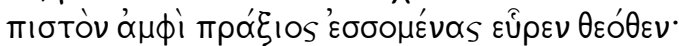

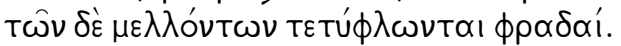

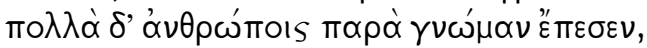

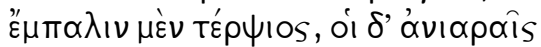

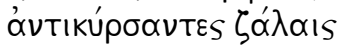

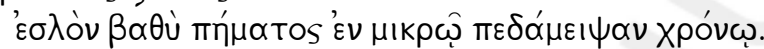

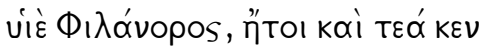

$\varepsilon \pi$.

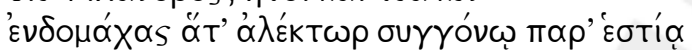

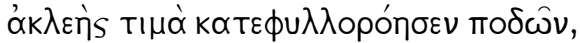

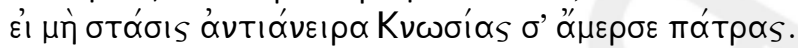

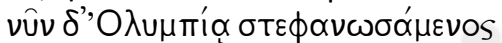

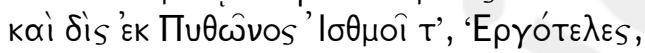

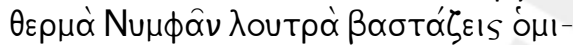

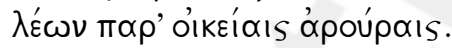

\section{Olímpica 12}

a Ergóteles de Himera, corredor

Rogo, filha de Zeus Libertador,

estrofe

Sorte salvadora, cuida de Himera de ampla força,

porque por ti, no mar, são governadas as velozes

naus e, na terra, ágeis guerras

e assembleias deliberativas. As esperanças dos homens,

muitas para cima, outras para baixo, se revolvem, cortando mentiras de vento.

Sinal confiável de deus a respeito de uma ação futura

antístr.

nunca ninguém sobre a terra encontrou:

as indicações são cegas para o que acontecerá.

Muitas coisas ocorrem aos humanos além de seu juízo, contra o prazer. Mas alguns, em dolorosos turbilhões se encontrando, trocam o sofrimento por um profundo bem em curto tempo.

Filho de Filánor, com certeza também, epodo como um galo que briga em casa, junto ao congênito lar tua glória dos pés perderia as folhas, sem fama, se a guerra civil que opõe os homens não te despojasse da pátria Cnossos.

Mas agora que em Olímpia foste coroado e duas vezes em Píton e no Istmo, Ergóteles, exaltas os banhos quentes das ninfas,

habitando terras próprias. 


\section{Comentário}

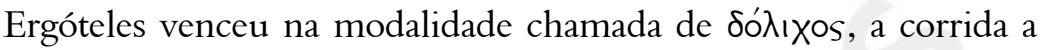
pé de longa distância. A distância percorrida é incerta, mas é provável que fosse cerca de cinco mil metros. ${ }^{2}$ A datação da Olímpica 12 não é totalmente segura e comentadores oscilam entre 470 e $466 .{ }^{3}$ Barrett compara a lista de vitórias de Ergóteles em Pausânias (6. 4. 11), o que pode ser lido da inscrição de sua estátua de vencedor olímpico (SEG [Supplementum epigraphicum Graecum] II. 1223 a = CEG [Carmina epigraphica Graeca] 393) e os escólios, para propor que os estudiosos alexandrinos se enganaram devido ao fato de o poema mencionar primeiro a vitória olímpica. A ode, na verdade, seria em comemoração a uma vitória pítica, em $466 .^{4}$

Dois fatos políticos são relevantes para o entendimento do contexto em que a ode foi apresentada. O primeiro é mencionado diretamente na ode, o exílio do vencedor de sua terra natal, Cnossos, e acolhida em Himera. Barrett propõe que Ergóteles recebeu a cidadania de sua nova cidade em 476 ou 475, conforme a história política de Himera

${ }^{2}$ Cf. Miller, S. G. Arete: Greek sports from ancient sources. Third and expanded edition. Berkeley: University of California Press, 2004, p. 216.

${ }^{3}$ Cf. Finley Jr., J. H. Pindar and Aeschylus. Cambridge, Mass.: Harvard University Press, 1966, p. 147/ Verdenius, W.J. Commentaries on Pindar. Volume I, "Olympian Odes" 3, 7, 12, 14. Leiden: Brill, 1987, p. 89/Des Places, E. Pindare et Platon. Paris: Beauchesne et ses fils, 1949, p. 16.

${ }^{4}$ Cf. Barrett, W. S. Pindar's "Twelfth Olympian" and the fall of the "deinomenidai". The journal of Hellenic studies. Cambridge, vol. XCIII, p. 24-27, 1973. Segundo Pausânias (6. 4. 11): "Ergóteles filho de Filánor venceu duas vezes a corrida de longa distância em Olímpia e a mesma quantidade em Delfos, no Istmo e em Nemeia. Dizem que ele não era originário de Himera, conforme a inscrição em sua estátua, mas cretense de Cnossos. Banido de Cnossos por inimigos políticos, foi para Himera, recebeu cidadania e ainda encontrou outras honras. É razoável então que acabe sendo aclamado como nativo de Himera nos jogos". Talvez a fonte de Pausânias sobre a vida política de Ergóteles seja a própria Olímpica 12. Conforme Barrett, conferindo a lista de vencedores dos papiros de Oxirrinco (P. Oxy. $222=$ F. Gr. Hist. 415), não há como datar as vitórias ístmicas e nemeias, mas as olímpicas são de 472 e 464, e as píticas de 470 e 466 . O epigrama inscrito em bronze diz: "Ergóteles me dedicou [...] vencendo os gregos na corrida de longa distância duas vezes na Pítia, duas vezes em Olímpia, duas vezes no Istmo e duas vezes em Nemeia, sendo para Himera uma memória imortal de excelência”. Cf. Thomas, R. Fame, memorial, and choral poetry: the origins of epinikian poetry. An historical study. In: Hornblower, S.; Morgan, C. (org.). Pindar's poetry, patrons and festivals. From archaic Greece to the Roman Empire. Oxford: Oxford University Press, 2007, p. 141-166, p. 159. 
narrada por Diodoro (9.48.6 a 9.49.3), quando Terão teria concedido a cidadania aos estrangeiros que a desejassem, após ter esvaziado a cidade num massacre de opositores. ${ }^{5}$ O segundo fato é a libertação política de Himera, que estava até 470 sob domínio de Trasideu de Ácragas e depois, até 466 ou 465, foi dominada por Trasíbulo da Siracusa. ${ }^{6}$

Crotty resume a estrutura da ode em: prece - gnome - elogio do vencedor. ${ }^{7}$ Bundy a descreve da seguinte forma: a estrofe é uma Priamel terminando em gnome de oposição, em forma de invocação. A antístrofe explica a gnome e o epodo usa as vicissitudes da estrofe e da antístrofe para mostrar a mudança de sorte de Ergóteles no sucesso esportivo. ${ }^{8}$

A estrofe, a prece a Túxa, é a seguinte (O. 12, 1-6b):

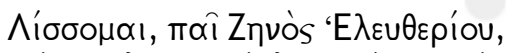
'I

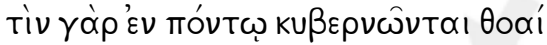

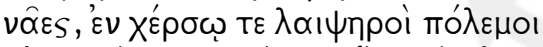

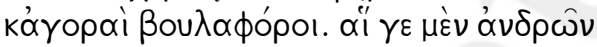

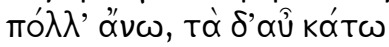

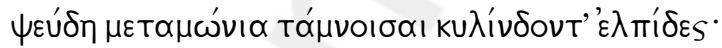

Rogo, filha de Zeus Libertador,

Sorte salvadora, cuida de Himera de ampla força,

porque por ti, no mar, são governadas as velozes

naus e, na terra, ágeis guerras

e assembleias deliberativas. As esperanças dos homens,

muitas para cima, outras para baixo,

se revolvem, cortando mentiras de vento.

Túxa, a quem a prece é dirigida, só aparece no final do segundo verso. É o poder divino imprevisível que faz as coisas acontecerem do

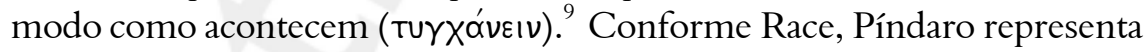

${ }^{5}$ Cf. Barrett, op. cit., p. 23-24.

${ }^{6}$ Cf. Barrett, op. cit., p. 30-31.

${ }^{7}$ Cf. Crotty, K. Song and action. Baltimore: The Johns Hopkins University Press, 1982, p. 11.

${ }^{8}$ Cf. Bundy, E. Studia pindarica. Los Angeles: University of California Press, 1986, p. 51-52; p. 36 (nota 6).

${ }^{9}$ Cf. Verdenius, op. cit., p. 91./ Cf. Silk, M. Pindar's poetry as poetry. A literary commentary on “Olympian 12”. In: Hornblower, S.; Morgan, C. (org.). Pindar's poetry, patrons and festivals. From archaic Greece to the Roman Empire. Oxford: Oxford University Press, 2007, p. 177-197, p. 183. 
Túxa em seus epinícios sempre com o papel positivo da boa sorte enviada pela divindade. ${ }^{10}$ Antes da menção do nome, a primeira caracterização que recebe é a de "filha de Zeus Libertador". Embora um culto local não seja necessário para a invocação funcionar no poema, Barrett sugere a possibilidade de um culto a Zzùs 'E $\lambda \varepsilon \cup \theta$ épı anual que comemora o aniversário de destronamento de Trasíbulo em Siracusa. Lá chegaram inclusive a erigir uma estátua de Zeus Libertador. ${ }^{11}$ A relação de parentesco, um recurso para relacionar ideias abstratas desde Hesíodo, insere a Túx $\propto$ no mundo ordenado por Zeus. ${ }^{12}$ Antes de justificar a prece com a explicitação do poder da Sorte e depois relacioná-la com a história de vida do vencedor homenageado, Píndaro a associa a Zeus e à libertação política de Himera, uma vez que Zzùs 'E $\mathrm{\lambda} \varepsilon u \theta$ épı Burnett, está diretamente ligado à autonomia e liberdade de uma cidade em relação ao domínio estrangeiro. ${ }^{13} \mathrm{O}$ adjetivo que antecede seu nome é $\sigma \omega ́ \tau \varepsilon ı р \alpha$, "salvadora", para Verdenius também dotado de conotações políticas. ${ }^{14}$ Além dessa possível conotação, antecipa a relação com o campeão e a mudança de sorte ao longo de sua vida.

A partir do terceiro verso aparece o motivo da invocação a Túx $\propto$ e uma pequena lista que representa sua esfera de ação. Ela pilota as naus velozes no mar e, na terra, as ágeis guerras e as assembleias deliberativas. Bundy nota como "mar" e "terra" funcionam aí como pares universalizantes. ${ }^{15}$ Para Barrett, a navegação, o combate em terra e as assembleias são elementos que fazem parte da libertação da cidade. ${ }^{16}$ É mais uma vez uma possível conotação política. A guerra e a assembleia fazem parte das relações políticas entre os homens. A navegação é associada não só aos combates navais, mas também à atividade comercial. ${ }^{17}$ Esses

10 Cf. Race, W. H. Elements of plot and the formal presentation in Pindar's "Olympian 12". The classical journal. Chicago, vol. XCIX, n. 4, p. 373-394, 2004.

11 Cf. Barrett, op. cit., p. 35./ Diodoro, 9, 72, 2.

12 Cf. Verdenius, op. cit., p. 89-90.

13 Cf. Burnett, A. P. Pindar's songs for the young athletes of Aigina. Oxford: Oxford University Press, 2005, p. 112-113.

14 Cf. Verdenius, op. cit., p. 90.

15 Cf. Bundy, op. cit., p. 24 (nota 56).

16 Cf. Barrett, op. cit., p. 35.

17 Semelhante à Túxa filha de Zeus Libertador, nos primeiros cinco versos da Pítica 8, 'Houxía, a Calma, filha da Justiça - a quem é pedido que aceite a vitória do vencedor homenageado - tem as chaves supremas das assembleias (ßou $\hat{\alpha} v)$ e das 
elementos parecem aqui representar a atividade humana em geral. Os versos seguintes dão suporte a essa leitura, trazendo a ' $\varepsilon \lambda \pi{ }^{\prime}$ 's, uma palavrachave da abordagem tradicional da condição de vida humana na poesia grega. Isso permite a relação que faz Clay entre a função de Túx a na Olímpica 12 e da Hécate na Teogonia, o exercício de um poder arbitrário sobre o sucesso e a falha de cada ação humana. ${ }^{18}$ A consequência é a importância de Túxa para descrever a relação entre o vencedor e a vitória. ${ }^{19}$ Como observa Verdenius, embora a sorte determine o resultado das atividades humanas, as considerações prévias do homem sobre essas atividades são instáveis e, como mostram os versos seguintes, a alternância entre boa e má sorte enfatiza a fragilidade dos empreendimentos humanos. ${ }^{20}$ Como observa Race, do verso 5 ao final da estrofe há um hipérbato - figura de linguagem em que um sintagma composto por duas palavras é separado por outras palavras ou sintagmas entremeados, que não pertencem a ele - em que doze palavras (ou 13, contando com o $\delta^{\prime}$ ) estão entre o artigo đi', no verso 5 , e o substantivo ' $\varepsilon \lambda \pi^{\prime} \delta \varepsilon s$, no fim da estrofe. Até a última palavra, o sujeito da oração permanece um mistério. ${ }^{21}$ Esse hipérbato sugere a própria espera que circunda as incertezas. Conforme Burnett, Píndaro segue a tradição de representar a instabilidade e o engano da esperança, embora ela seja uma resposta comum a uma situação de sofrimento e, acrescento, ao objetivo incerto da superação atlética (como em Pítica 8,90$).{ }^{22}$ As esperanças rolam ora para cima, ora para baixo e cortam mentiras de vento. $O$ adjetivo que caracteriza mentiras, $\mu \varepsilon \tau \alpha \mu \omega ́ v ı \alpha$, tem o sentido de "o que é levado pelo vento" e, portanto, "vão", reforçando a falta de substância e a inconstância dessas mentiras. Comentadores como Silk chamam atenção para as imagens relacionadas ao mar, iniciadas pelo governo da Túxa sobre as

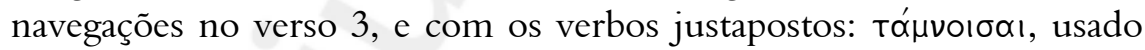

guerras, o que abarca a política interna e externa, em situações de guerra e paz. Nos versos 6 e 7, Píndaro acrescenta que a Calma sabe assumir uma atitude passiva ou ativa de forma adequada, o que é pertinente quanto à esfera política, mas abre a possibilidade para a ação humana em geral, incluindo a atividade esportiva.

${ }^{18}$ Cf. Clay, J. S. Hesiod's cosmos. Cambridge: Cambridge University Press, 2003, p. 135.

${ }^{19}$ Cf. Crotty, op. cit., p. 65.

${ }^{20}$ Cf. Verdenius, op. cit., p. 93; p. 50.

${ }^{21}$ Cf. Race, F. "Hyperbata” in Pindar's "Odes". The classical journal. Chicago, vol. XCVIII, n. 1,2002, p. 21; p. 27.

${ }^{22}$ Cf. Burnett, op. cit., p. 111-112. Burnett enumera outras passagens além de O. 12, 6 em que Píndaro caracteriza assim a $\varepsilon \lambda \pi^{\prime} i_{s}: O .13 .83, P .3 .23, N .8 .45$.

${ }^{23}$ Cf. Verdenius, op. cit., p. 94. 


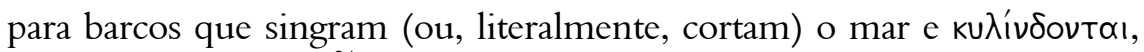

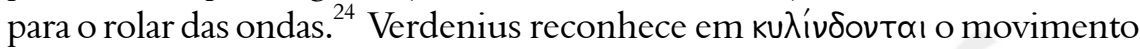
irregular em contraste com o controle representado pelo verbo

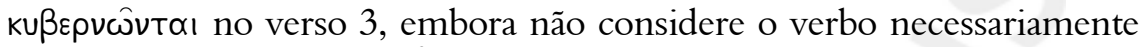
ligado à imagem da onda. ${ }^{25}$ Ainda assim, o mar associado a incertezas e vicissitudes não parece uma imagem improvável na literatura grega, considerando sua representação na Odisseia, como lugar em que Odisseu sofre e se perde, e em Trabalhos e Dias, como lugar de atividades mais incertas e perigosas do que a agricultura.

A caracterização das $\varepsilon \lambda \pi \pi^{\prime} \delta \varepsilon s$, segundo Crotty, seria formada por uma expressão de incerteza ("muitas para cima, outras para baixo"), uma de frustração ("mentiras de vento") e uma de falta de rumo ou objetivo

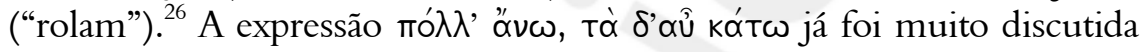
por comentadores. Bundy a inclui em sua lista de expressões de alternância. ${ }^{27}$ Verdenius sugere que o sentido de "para cima" e "para baixo" não é correto, por não ser característico do movimento de um navio que perde seu curso. O correto seria uma expressão como "para cá" e "para lá", de movimento horizontal, que seria o movimento sugerido pelo verbo ku $\lambda i ́ v \delta o \mu \alpha ı .{ }^{28}$ Race considera que esse significado só seria possível com as

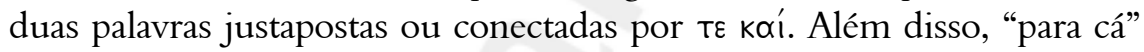
e "para lá" teria um sentido de movimento vacilante ou sem rumo, enquanto "para cima" e "para baixo" têm conotações de sucesso e falha, como em Pítica 8, 92-94. ${ }^{29}$ Silk considera que não se trata de uma expressão sobre as vicissitudes e a sorte humana, mas apenas negativa, com o uso de ${ }^{\prime} \nu \omega$ e kó́t $\omega$ para designar confusão em assuntos diversos. ${ }^{30}$ A conotação de fracasso e sucesso parece interessante numa ode a um atleta, assim como a ideia de variação de condição parece estreitamente ligada à ' $\varepsilon \lambda \pi$ ís e Túxa. ${ }^{31}$ O homem, portanto, singra sem muita certeza, jogado por um mar de engano e ilusão.

${ }^{24}$ Cf. Silk, op. cit., p. 185.

${ }^{25}$ Cf. Verdenius, op. cit., p. 95.

${ }^{26}$ Cf. Crotty, op. cit., p. 9.

${ }^{27}$ Cf. Bundy, op. cit., p. 7 (nota 23).

${ }^{28}$ Cf. Verdenius, op. cit., p. 93.

${ }^{29}$ Cf. Race, op. cit., 2004, p. 379-380.

${ }^{30}$ Cf. Silk, op. cit., p. 185.

${ }^{31}$ Mas se é necessário corresponder também ao movimento do navio da imagem, poder-se-ia pensar no movimento vertical do mar revolto. 
$\mathrm{Na}$ antístrofe, uma sequência gnômica que explica as imagens da estrofe (Olimpica 12, 7-12b):

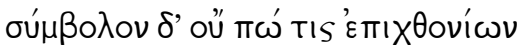

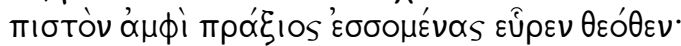

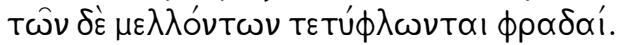

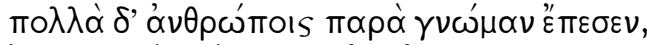

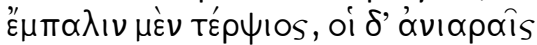

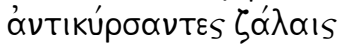

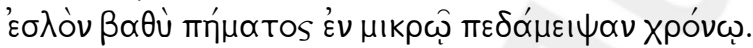

Sinal confiável de deus a respeito de uma ação futura

nunca ninguém sobre a terra encontrou:

as indicações são cegas para o que acontecerá.

Muitas coisas ocorrem aos humanos além de seu juízo,

contra o prazer. Mas alguns, em dolorosos

turbilhões se encontrando,

trocam o sofrimento por um profundo bem em curto tempo.

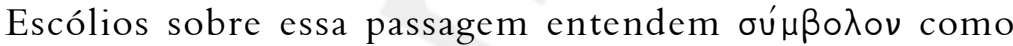
"presságio", embora literalmente seja "sinal de reconhecimento" ou "marca de identificação". ${ }^{22}$ No caso, trata-se de um sinal confiável sobre o futuro. $\Theta \varepsilon o ́ \theta \varepsilon v$, que indica a origem divina do sinal e, portanto, o conhecimento dos deuses quanto ao futuro, é a última palavra do verso 8, estabelecendo um contraste com os humanos habitantes da terra, assim identificados pela última palavra do verso 7 , que nunca têm acesso a esse tipo de conhecimento. O adjetivo mı́óv, "confiável”, é significativo, porque pressupõe a existência de sinais falsos, como os enganos provocados pela esperança. Verdenius e Silk comentam que os sinais divinos são ocultos ou obscuros e por isso não confiáveis. ${ }^{33}$

Pensando nos sinais que deuses enviam na Ilíada e Odisseia, eles podem não ser confiáveis por serem propositalmente enganosos ou por serem tentativas humanas de considerar algum acaso qualquer como sinal divino. O verbo eûpev pode ter o significado de "achar por acaso", por simplesmente se deparar com algo notável, mas também o de "encontrar como resultado de uma busca". Mesmo que os homens tentem, tudo o que for considerado sinal divino não pode ser verificado pela mente humana. O pensamento ou juízo humano ( $\gamma v \omega \dot{\mu \alpha})$ é insuficiente.

\footnotetext{
${ }^{32}$ Cf. Silk, op. cit., p. 186/Verdenius, op. cit., p. 95.

${ }^{33}$ Cf. Verdenius, op. cit., p. 96/ Silk, op. cit., p. 186.
} 
Assim, o verso 9 é quase uma repetição do que já foi dito: a

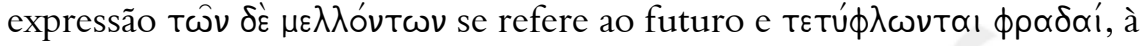
incapacidade de conhecê-lo. A última expressão acrescenta, porém, uma metáfora. Race indica que a palavra $\phi \rho \alpha \delta \alpha i ́$ aqui tem uma interpretação tradicional de "percepções" ou "conhecimentos" seguindo um escólio

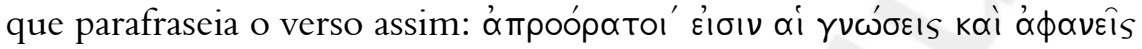

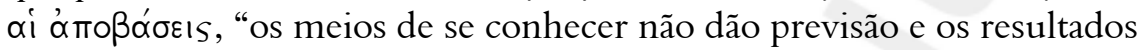
não são visíveis", mas a palavra costuma significar "conselhos" ou "avisos", especialmente aqueles dados por um deus, como os sinais do verso $7 .{ }^{34}$ O verbo тєтú $\phi \lambda \omega \nu \tau \alpha ı$ significa "cegar" ou "estar cego". Como Silk explica, o significado de "estar cego" é aplicado à mensagem (a indicação ou aviso), em vez de referir-se àqueles que a recebem. ${ }^{35}$ Sinais ou avisos não antecipam com clareza a visão do que ainda não aconteceu.

A consequência, nos versos 10 e 11, é que muitas coisas acontecem de modos que não correspondem àquilo que um homem julgaria acontecer, contrárias a um prazer ou resultado positivo esperado. Isso retoma o tema da ' $\varepsilon \lambda \pi$ ís e completa a relação entre a incerta esperança e a impossibilidade de conhecer o que acontecerá. Day, entretanto, propõe que em Píndaro o tema da '̇̀mís não é totalmente negativo, correspondendo à espera por tornar a proeza realizada imortal através da memória da poesia. ${ }^{36}$ Essa positividade aparece na Olímpica 12 a partir do verso 11 , com o oi $\delta$ ' marcando o início de uma adversativa que muda o curso das considerações sobre a imprevisibilidade do futuro, até então relacionada à insegurança e frustração: alguns homens, encontrando-se em dolorosos turbilhões, em pouco tempo trocam o sofrimento por um profundo bem. Para Greengard, esses versos reforçam a imagem marítima da estrofe, principalmente pela correspondência métrica. ${ }^{37}$ Para Verdenius, a palavra $\zeta \alpha^{\prime} \lambda \alpha$ เs, "turbilhões" ou uma "agitação violenta", mas, sobretudo, de ondas, não é o bastante para formar uma imagem marítima recorrente, porque, na República de Platão (486d7), ela é usada para uma situação de tempestade em terra. ${ }^{38}$ Ainda assim, é uma imagem de água em movimento violento. A mudança de condição

\footnotetext{
${ }^{34}$ Cf. Race, op. cit., 2004, p. 381.

${ }^{35}$ Cf. Silk, op. cit., p. 186-187.

${ }^{36}$ Cf. Day J. W. The poet's "elpis" and the opening of "Isthmian 8". Transactions of the American philological association. Baltimore, vol. CXXI, p. 51, 1991.

${ }^{37}$ Cf. Greengard, C. The structure of Pindar's epinician odes. Amsterdam: Adolf M. Hakkert Publisher, 1980, p. 21.

${ }^{38}$ Cf. Verdenius, op. cit., p. 97.
} 


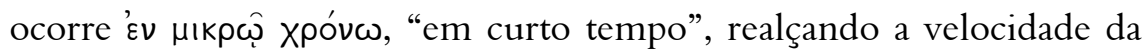

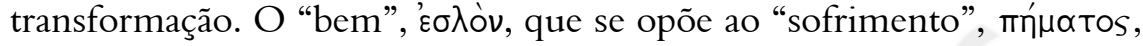
é caracterizado como $\beta \alpha \theta \dot{u}$, "profundo", enfatizando que a mudança não é apenas rápida, mas ainda ocorre entre condições extremas. Embora seja um adjetivo de muitos usos, Silk sugere que $\beta \alpha \theta i$, pela proximidade de $\zeta \alpha ́ \lambda \alpha ı s$, evoca águas profundas, o que também faz parte do jogo de imagens marítimas construído na ode. ${ }^{39}$ A guinada para uma visão positiva das variações da sorte, como observa Barrett, corresponde principalmente ao próprio caso de Ergóteles, vitorioso após a derrota em Cnossos, e também ao de Himera, livre depois de duas tiranias. ${ }^{40}$

Assim, Píndaro construiu o momento adequado para introduzir na ode o vencedor homenageado e concluí-la com sua vitória pessoal (O. 12, 13-19b):

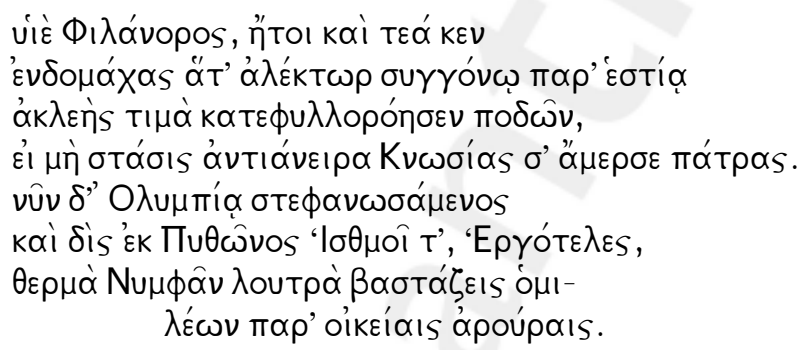

Filho de Filánor, com certeza também, como um galo que briga em casa, junto ao congênito lar tua glória dos pés perderia as folhas, sem fama, se a guerra civil que opõe os homens não te despojasse da pátria Cnossos. Mas agora que em Olímpia foste coroado e duas vezes em Píton e no Istmo, Ergóteles, exaltas os banhos quentes das ninfas,

habitando terras próprias.

O vencedor aparece primeiro como o filho de Filánor, conforme a tradição de prestar homenagem à família, e, finalmente, como Ergóteles, após sua realização plena com as vitórias. Com uma construção condicional,

\footnotetext{
${ }^{39}$ Cf. Silk, op. cit., p. 188. Silk também compara a escolha de palavras de Píndaro no verso 12 ao verso 530 do canto XXIV da Ilíada, parte do discurso consolatório de

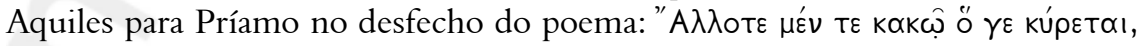
' de condição está presente nos dois trechos./ Cf. Silk, op. cit., p. 187-188.

${ }^{40}$ Cf. Barrett, op. cit., p. 35.
} 
o epodo mostra o efeito inesperadamente positivo da Túxa na vida do atleta. $\mathrm{O}$ bem atual é consequência imprevista da desgraça inicial.

No verso 14, aparece a imagem do galo. Rinhas eram comuns em toda a Grécia, ${ }^{41}$ mas Hamilton observa que o galo era cunhado nas moedas de Himera e, com o estabelecimento da democracia, passaram a ser cunhadas uma carruagem e uma ninfa com um banhista, imagem semelhante à do verso 19 , de modo que seria mais um detalhe a representar a mudança positiva da condição da cidade e da vida de Ergóteles. ${ }^{42} \mathrm{O}$ verso 15 completa a imagem, "tua glória dos pés perderia as folhas, sem fama". "Perder as folhas" é uma alusão à coroa dada ao

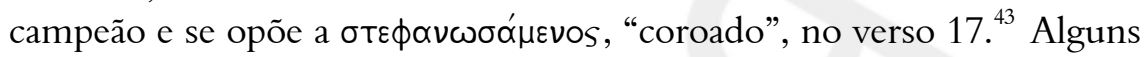
comentadores relacionaram essa imagem das folhas à de Homero em Ilíada 6, 146-149, mas o único ponto de contato possível entre a imagem da Ilíada e a de Píndaro seria o desfolhar como perda ou fim, em Homero da vida humana e, em Píndaro, da glória. Ainda assim, na Olímpica 12 não há a indicação de renovação. ${ }^{44}$ O galo é o lutador doméstico, como o atleta poderia ter sido apenas um competidor doméstico; a glória dos pés do vencedor, ou o valor de sua habilidade como corredor, é como a árvore que teria perdido suas folhas. ${ }^{45}$ Se Ergóteles não tivesse que abandonar sua terra natal, sua glória não teria reconhecimento ('ák $\lambda \varepsilon \eta_{S}$ тı $\mu \alpha$ ), porque feitos de um vencedor local têm apenas uma repercussão limitada, como os de um galo que só briga no quintal de casa.

O verso 16 é a prótase da condicional, trazendo o passado negativo

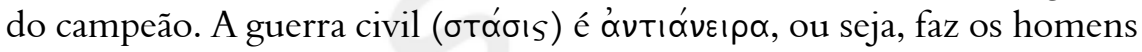
lutarem uns contra os outros, e como resultado Ergóteles precisa deixar sua terra natal. Race observa que a condicional estabelece uma conexão lógica na estrutura do poema entre dois eventos aparentemente não relacionados e torna a expulsão da terra natal um fato essencial para o sucesso de Ergóteles. ${ }^{46}$ A breve menção desta história é usada para proporcionar

\footnotetext{
${ }^{41}$ Cf. Verdenius, op. cit., p. 99.

${ }^{42}$ Cf. Hamilton, R. "Olympian 12" and the coins of Himera. Phoenix. Toronto, vol. XXXVIII, n. 3, p. 261-264, 1984.

${ }^{43}$ Cf. Verdenius, op. cit., p. 99.

${ }^{44}$ Cf. Verdenius, op. cit., p. 99-100; cf. Silk, op. cit., p. 190. Os dois comentadores não acham a comparação pertinente, uma vez que a imagem de Homero se refere à alternância de gerações e insignificância do indivíduo.

${ }^{45}$ Cf. Hoey, T. Fusion in Pindar. Harvard studies in classical philology. Cambridge, Mass.,vol. LXX, p. 247-248, 1965.

${ }^{46}$ Cf. Race, op. cit., 2004, p. 384.
} 
um contraste máximo com o verso seguinte. Com vûv $\delta$ ', "mas agora", Píndaro volta ao presente e ao motivo da celebração, a vitória nos jogos, o profundo bem após o turbilhão de sofrimentos. No verso 19, há o encerramento da ode com a agradável situação atual do vencedor e a

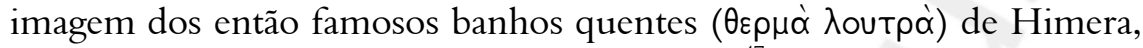
que funcionam como metonímia para a cidade. ${ }^{47}$ Hamilton mostra como

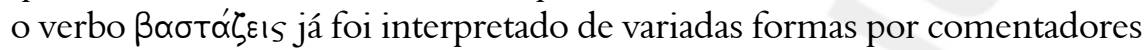
diversos, seja seguindo a indicação de escoliastas, com um sentido metafórico de "erguer e aumentar a fama de Himera" - conhecida pelas fontes termais - ou, num sentido literal, de "erguer a água para tomar

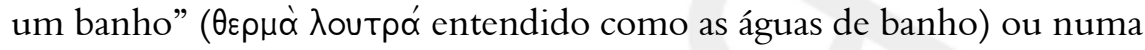
tentativa de dois sentidos simultâneos, algo como "abraças os banhos quentes". Hamilton prefere uma interpretação não totalmente metafórica, por causa da figura do banhista que acompanha uma possível ninfa nas moedas de Himera, que poderia indicar o movimento de banho atribuído a Ergóteles. ${ }^{48}$ Race sugere que o movimento para cima de

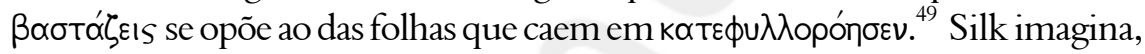
também num sentido misto entre o literal e o metafórico, Ergóteles tomando das águas com as mãos, como numa expressão de seu sentimento de estar em casa. ${ }^{50}$ De todo modo, indica o momento positivo do vitorioso também com uma imagem relacionada à água. A expressão

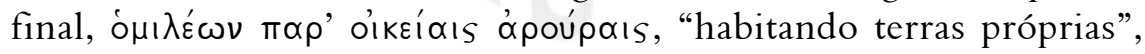
acrescenta ao momento positivo a integração social de Ergóteles na terra que se tornou sua casa.

O movimento do poema, pelas incertezas até chegar à realização positiva quando as circunstâncias pareciam tão adversas, é como a variação da vida de Ergóteles e da política de Himera. As imagens relativas à água são construídas de forma a também acompanhar esse curso: o governo imprevisível de Túxa sobre as naus no mar, as esperanças em arrebentação, os turbilhões dolorosos da tempestade, e o final feliz dos banhos quentes das ninfas, que opõe o conforto de casa à violência e inconstância do mar.

Essa reinterpretação dos desastres passados em vista de sucessos atuais é o que Mackie observa também em outras odes. O curso da Olímpica 12 pode ser comparado ao do relato mítico da Olímpica 7 -

\footnotetext{
${ }^{47}$ Cf. Silk, op. cit., p. 194.

${ }^{48}$ Cf. Hamilton, op. cit., p. 261-262.

${ }^{49}$ Cf. Race, op. cit., 2004, p. 380.

${ }^{50}$ Cf. Silk, op. cit., p. 194.
} 
elemento que inclusive não faz parte da ode comentada. Os três mitos sobre os ancestrais do vencedor no princípio da história de Rodes mostram como um evento que inicialmente parecia desastroso, um erro terrível, leva a uma conclusão positiva. Também a Olímpica 2 relata os terríveis mitos tebanos em uma perspectiva de alternância, em que sofrimentos podem ser compensados por uma alegria subsequente, o que na ode também é relacionado à situação do vencedor. ${ }^{51}$ Race compartilha a comparação com o mito de Tlepólemo na Olímpica 7 e acrescenta que em Píndaro os três Eácidas, Peleu, Télamon e Teucro, são exilados que encontram novas cidades. Ele expande a comparação para a tragédia e a poesia em geral, afirmando que se trata de um lógos típico, em que um homem é exilado de sua terra natal (seja por um assassinato ou expulsão política), mas a sorte transforma o desastre em bem, estabelecendo esse homem em uma nova terra onde ele tem seu valor reconhecido. Seria o padrão do Édipo de Sófocles em Édipo em Colono, de Fênix e Pátroclo na Ilíada, e de Eumeu e Teoclímeno na Odisseia. ${ }^{52}$

Assim, se a ação e a existência humana acontecem nos domínios da contingência (do "que pode ser de outra maneira", т⿳亠口 $\delta$ ' ' $v \delta \delta \varepsilon \chi o ́ \mu \varepsilon v \alpha$

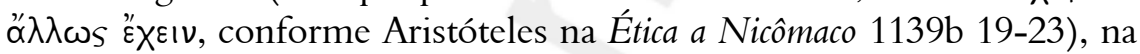
Olímpica 12, apesar de reconhecer o risco da esperança, Píndaro mostra como as constantes variações e a impossibilidade de se prever o futuro podem resultar numa reversão positiva de condições, em que uma situação adversa dá lugar ao sucesso, mesmo quando isso parecia pouco provável.

\section{Referências}

BARRETT, W. S. Pindar's "Twelfth Olympian" and the fall of the "deinomenidai". The journal of Hellenic studies. Cambridge, vol. XCIII, p. 23-35, 1973.

BUNDY, E. Studia pindarica. Los Angeles: University of California Press, 1986.

BURNETT, A. P. Pindar's songs for the young athletes of Aigina. Oxford: Oxford University Press, 2005.

CLAY, J. S. Hesiod's cosmos. Cambridge: Cambridge University Press, 2003.

CROTTY, K. Song and action. Baltimore: The Johns Hopkins University Press, 1982.

${ }^{51}$ Cf. Mackie, H. Graceful errors. Pindar and the performance of praise. Ann Arbor: The University of Michigan Press, 2003, p. 74; p. 83-84.

${ }^{52}$ Cf. Race, op. cit., p. 390. 
DAY, J. W. The poet's "elpis" and the opening of "Isthmian 8". Transactions of the American philological association. Baltimore, vol. CXXI, p. 47-61, 1991.

DES PLACES, E. Pindare et Platon. Paris: Beauchesne et ses fils, 1949.

FINLEY Jr., J. H. Pindar and Aeschylus. Cambridge, Mass.: Harvard University Press, 1966.

GREENGARD, C. The structure of Pindar's epinician odes. Amsterdam: Adolf M. Hakkert Publisher, 1980.

HAMILTON, R. "Olympian 12" and the coins of Himera. Phoenix. Toronto, vol. XXXVIII, n.3, p. 261-264, 1984.

HOEY, T. Fusion in Pindar. Harvard studies in classical philology. Cambridge, Mass., vol. LXX, p. 235-262, 1965.

MACKIE, H. Graceful errors. Pindar and the performance of praise. Ann Arbor: The University of Michigan Press, 2003.

MILLER, S. G. Arete: Greek sports from ancient sources. Third and expanded edition. Berkeley: University of California Press, 2004.

PÍNDARO. Pindari carmina cum fragmentis. Editado por H. Maehler (post B. Snell). Leipzig: Teubner, 1971.

RACE, W. H. Framing "hyperbata" in Pindar's "Odes". The classical journal. Chicago, vol.XCVIII, n. 1, 2002, p. 21-33.

RACE, W. H. Elements of plot and the formal presentation in Pindar's "Olympian 12". The classical journal. Chicago, vol. XCIX, n. 4, p. 373-394, 2004.

SILK, M. Pindar's poetry as poetry. A literary commentary on "Olympian 12". In: HORNBLOWER, S.; MORGAN, C. (org.). Pindar's poetry, patrons and festivals. From archaic Greece to the Roman Empire. Oxford: Oxford University Press, 2007, p. 177-197. THOMAS, R. Fame, memorial, and choral poetry: the origins of epinikian poetry. An historical study. In: HORNBLOWER, S.; MORGAN, C. (org.). Pindar's poetry, patrons and festivals. From archaic Greece to the Roman Empire. Oxford: Oxford University Press, 2007, p. 141-166.

VERDENIUS, W. J. Commentaries on Pindar. Volume I, "Olympian Odes" 3, 7, 12, 14. Leiden: Brill, 1987. 